\title{
Simulation with standardized patients: nursing student's communication skills in health
}

\author{
Simulação com pacientes padronizados: habilidades de comunicação em saúde do estudante \\ de enfermagem
}

Fernanda dos Santos Nogueira de Góes ${ }^{1}$, Natália Del' Angelo Aredes ${ }^{1}$, Cristina Yuri Nakata Hara ${ }^{1}$, Luciana Mara Monti Fonseca ${ }^{1}$, Suzanne Hetzel Campbell ${ }^{2}$

Objective: to identify and measure nursing student's communication skills in health using simulation with standardized patients. Methods: descriptive, cross-sectional study carried out with 16 students of the last year of the nursing undergraduate course. The simulation focused on requesting authorization from the patient/ family to perform venipuncture. During the simulation, all the students were evaluated through the Health Communication Assessment Tool. Results: of the 22 items of the tool, 18 reached agreement higher than 50.0\%. Of the 16 participants, 14 (87.5\%) were assessed as being able to communicate in more than $50.0 \%$ of the statements. Conclusion: students' communication was satisfactory; there are gaps related to the emotional aspects of the patient and the family, manifesting the need to reinforce communication in the nursing curriculum. Descriptors: Education, Nursing; Patient Simulation; Communication; Students, Nursing.

Objetivo: identificar e medir as habilidades de comunicação em saúde do estudante de enfermagem usando simulação com paciente padronizado. Métodos: descritivo, transversal, realizado junto a 16 estudantes do último ano da graduação em enfermagem. A simulação centrou-se na solicitação de autorização do paciente/família para realizar punção venosa. Durante a simulação, todos os alunos foram avaliados por meio da Ferramenta de Avaliação da Comunicação em Saúde. Resultados: dentre os 22 itens da ferramenta, 18 atingiram concordância superior a 50,0\%. Dos 16 participantes, $14(87,5 \%)$ foram avaliados como capazes de se comunicar em mais de 50,0\% das afirmações. Conclusão: a comunicação do estudante foi satisfatória; há lacunas relacionadas aos aspectos emocionais do paciente e família, manifestando necessidade de reforçar a comunicação no currículo de enfermagem.

Descritores: Educação em Enfermagem; Simulação de Paciente; Comunicação; Estudantes de Enfermagem.

\footnotetext{
${ }^{1}$ Escola de Enfermagem de Ribeirão Preto, Universidade de São Paulo. Ribeirão Preto, SP, Brazil.

${ }^{2}$ University of British Columbia. Vancouver, Canadá. 


\section{Introduction}

The importance of communication in nursing education is recognized in several documents that influence national and international educational policies $^{(1-2)}$. Communication is considered a key factor in patient-centered care ${ }^{(1)}$ and, therefore, it is essential to advance the education of health professionals from the adequacy of curricula, meeting the local needs and the use of different teaching strategies to improve training, respecting the culture of each country ${ }^{(3)}$.

Communication is understood as verbal and nonverbal behaviors that occur during interaction between two or more people. In the health context, verbal communication includes the use of appropriate language to the social and cultural context of the patient and his/her family; non-verbal communication includes behaviors such as smiles, gestures, facial expressions and eye contact, which will be used by people to interact with the message ${ }^{(4)}$.

Communication skills are essential for nursing area. However, this competence is not necessarily intuitive $^{(5)}$. Fragilities in the communicative capacity of nurses may bring concerns about humanized and inclusive care, especially in the context of patient safety and quality care ${ }^{(1)}$. Based on the assumption that communication forms the basis of nurses' work and that the world panorama shows weaknesses in training, finding innovative ways to teach nursing communication becomes urgent.

Thus, we are interested in the use of simulation with standardized patients (actors) as a teaching strategy aligned to the theoretical and conceptual references of nursing education ${ }^{(6)}$. Simulations have been used in nursing education, since they are defined as activities that replicate the practice environment ${ }^{(3,6-7)}$ and integrate the real world into the learning-teaching process in order to achieve the proposed educational objectives $^{(3)}$.

From the perspective of nursing student training, the use of simulated environments is unders- tood as an active learning possibility for the student's preparation in providing care quality for the patient, considering the social requirements and safety, widely discussed at the present time ${ }^{(6,8)}$. With regard to communication, simulations allow the teacher to evaluate verbal and non-verbal communication of students ${ }^{(4)}$, that is, it enables exploring students' skills beyond cognitive learning.

Simulation with standardized patients is translated by the employment of trained actors and has been increasingly globally used in universities and health services ${ }^{(9)}$.

We conducted a literature review in the Virtual Health Library and Scopus databases guided by the question: "what is the role of simulation with standardized patients, focusing on patient/family communication?" International studies have identified the perception of communication efficacy through the self-assessment of nursing students after and before tests. The findings showed a significant increase in self-confidence ${ }^{(5,10-11)}$, in knowledge and technical skills $^{(10)}$, and improved communication ${ }^{(5,10)}$.

Nursing students' communication skills were verified through simulation recorded with standardized patients. At the debriefing, students received feedback from the actors on the communication and watched the recording. Students perceived the importance of communication and attitudes that needed to be improved ${ }^{(12)}$. The simulation about communication increases the possibilities of teamwork and critical thinking skills ${ }^{(13)}$. This review has shown that communication can interfere with student confidence, problem-solving skills, and procedural skills. No Brazilian studies were found.

In view of these considerations, and due to the fact that simulation with standardized patients can be a significant experience for nursing students and the lack of Brazilian studies using a tool to evaluate communication, this study seeks to identify and measure nursing students' communication skills in health using simulation with standardized patients. 


\section{Methods}

This is a descriptive and cross-sectional study developed in a nursing undergraduate course of a public institution in the state of São Paulo. Data collection took place in April 2016. The course offers 50 vacancies, has a workload of 4,485 hours in five years and, in addition to graduating bachelors in nursing, it also graduates licensed nurses to act as teachers in professional nursing education and to develop health education actions with children and adolescents in basic education.

Only the 44 students of the last year of the nursing undergraduate course were invited, since it is understood that after being exposed to all course subjects, the cumulative effect of teaching programs on communication skills would be manifested in their actions during the simulation. No inclusion/ exclusion criteria were defined, since, according to the school's regulations, only students who fulfilled all previous credits could be enrolled in disciplines of the last year of the course. All forty-four students received up to three invitations via e-mail. Of these, sixteen $(36.3 \%)$ accepted to participate in the pilot test; the non-response to the invitation of the twentyeight other students was interpreted as refusal. As the students knew all the researchers, the invitation was not carried out in an attempt to avoid bias on power relations; therefore, it is not possible to identify the reasons for refusal.

Two instruments were used; a questionnaire for characterizing participants and the Health Communication Assessment Tool to measure communication skills during the simulation ${ }^{(6)}$. The Health Communication Assessment Tool presents 22 Likert scale statements; number one indicates the lowest level, and five indicates the highest level of communication. The tool was developed in the United States and validated in Brazil by researchers.

In order to guarantee consistency in data col- lection, a simulation scenario focused on communication was developed, whose purpose was to request authorization from the patient and family to perform a venipuncture. The actors were an elderly woman hospitalized on the sixth day of treatment with an intravenous antibiotic and her daughter, who was dissatisfied with her mother's condition and the numerous painful procedures performed on the patient by the team.

In doubles, students participated in the simulation, in a total of eight sessions. The duration of each briefing was 5-7 minutes (presentation of the problem, activity to be performed, learning objective) and the simulation lasted between 8-10 minutes. The debriefing took place over 20 minutes and ran through the phases: emotional (centered on the student's feeling), descriptive (by the student, from the experienced setting), evaluative (stimulating critical thinking about what they did to be positive), analytical (thinking and talking about what they would do differently in other situations) and conclusive (decision making and teamwork). During the simulation, a trained specialist completed the Health Communication Assessment Tool and the result was subsequently made available to the students who showed interest. Descriptive statistics was used using the personal computer version of the Statistical Package for the Social Sciences.

The study complied with the formal requirements contained in the national and international regulatory standards for research involving human beings.

\section{Results}

Of a total of 44 students, 16 accepted to participate in the study. The characterization of the participants is presented in Table 1. More than $60.0 \%$ of the participants participated in up to five simulations as actors; $25.0 \%$ of the students were observers in more than 11 simulations. 
Table 1 - Distribution of nursing students according to age group and previous participation in simulations

\begin{tabular}{lc}
\hline Variable & $\mathbf{\%}$ \\
\hline Age group (years) & 62.5 \\
$20-24$ & 31.3 \\
$25-29$ & - \\
$30-34$ & 6.3 \\
$35-40$ & \\
Number of participations in simulations & \\
As actors & 68.8 \\
$1-5$ & 31.3 \\
$6-10$ & \\
As observers & 43.8 \\
$1-5$ & 31.3 \\
$6-10$ & 25.0 \\
$11-15$ & \\
\hline
\end{tabular}

Table 2 shows the communication agreement and disagreements by tool items. Three items were adequately performed by $100.0 \%$ of students: "maintaining eye contact", "communicating what they were about to do before doing it" and "leaning toward the person." The items "spend equal or greater time addressing psychosocial aspects" and "asking about the patient/family's feelings" were not adequately performed by more than $75.0 \%$ of participants.

Communication per participant is shown in Table 3. Of the 16 participants, 14 (87.5\%) were evaluated as being able to communicate in more than $50.0 \%$ of the statements.

Table 2 - Scores by agreement in the Health Communication Assessment Tool according to each statement

\begin{tabular}{|c|c|c|c|c|c|c|}
\hline \multirow{2}{*}{ Student/Professional's statements } & \multicolumn{6}{|c|}{ Scores* (\%) } \\
\hline & 5 & 4 & 3 & 2 & 1 & n/a \\
\hline 1. Introduced her/himself to the patient and/or family. & 75.0 & - & - & - & 25.0 & - \\
\hline 2. Shacked the patient's and/or family member's hand or greeted appropriately. & 31.3 & 50.0 & - & - & 18.8 & - \\
\hline 3. Explained the reason for the visit in appropriate terms. & 62.5 & - & 31.3 & 6.3 & - & - \\
\hline 4. Used positive communication, including smile to encourage interactions. & 50.0 & 18.8 & 12.5 & 12.5 & 6.3 & - \\
\hline 5. Kept eye contact while talking to the patient and/or family. & 100.0 & - & - & - & - & - \\
\hline 6. Communicated what he/she was about to do BEFORE doing so. & 100.0 & - & - & - & - & - \\
\hline $\begin{array}{l}\text { 7. Asked the patient or family member whether he/she could touch the patient BEFORE doing a } \\
\text { procedure or exam (blood pressure, auscultation, venipuncture, probing, etc.). }\end{array}$ & 37.5 & 6.3 & - & 31.3 & 6.3 & 18.8 \\
\hline 8. Touched the patient appropriately. & 56.3 & - & - & - & 25.0 & 18.8 \\
\hline 9. Spent most of the time near the patient. & 93.8 & 6.3 & - & - & - & \\
\hline
\end{tabular}

11. Heard more than talked.

12. Leaned toward the speaker to show interest.

13. Effectively guided the patient and/or family about the procedure, illness, and/or treatment.

$37.525 .0 \quad-18.818 .8-$

14. Asked questions to encourage feedback and increase clarity. 100.0

15. Recognized and responded appropriately to the patient's and/or family's verbal and non-verbal behaviors (frowning, tears, hysteria, silence, etc.).

17. Avoided judging the patient/family's behaviors (e.g., economic condition, abuse, drug use, sexual orientation, religion/cultural differences, etc.).

$81.3 \quad-\quad-18.8--$ $75.012 .5-12.5-$ 18. Spent an equal or greater time approaching psychosocial aspects in patient/family care in relation to clinical (biological) aspects.

19. Asked about the patient/family's feelings about the situation, showing concern.

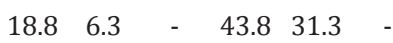

20. Acknowledged the conflict and tried to obtain information and find opportunities to minimize or manage it.

21. Developed, maintained or improved interpersonal relationship with the patient and/or family (through communication and professionalism).

22. Avoided technical health terms (vital signs, venipuncture, etc.) -include below the technical terms used.

*5 = I strongly agree; 4 = I agree; 3 = indecisive; 2 = I disagree; 1 = I strongly disagree; N/a = not applicable 
Table 3 - Scores per student, according to the sum of agreements ("I strongly agree" and "I agree") in the Health Communication Assessment Tool

\begin{tabular}{lc}
\hline Student & Agreements (\%) \\
\hline 1 & 86.3 \\
2 & 86.3 \\
3 & 86.3 \\
4 & 86.3 \\
5 & 86.3 \\
6 & 77.3 \\
7 & 77.3 \\
8 & 72.7 \\
9 & 72.7 \\
10 & 68.2 \\
11 & 68.2 \\
12 & 63.3 \\
13 & 59.1 \\
14 & 54.5 \\
15 & 45.5 \\
\hline
\end{tabular}

Although briefing and debriefing were not the focus of the study, several students reported surprise during debriefing about the presence of actors as a standardized patient, expressing satisfaction with this format because they find it more difficult to communicate with a manikin due to the absence of facial expressions during interaction. Most of the students reported feeling in a real situation and stated this activity should be performed in the first year of the course, before direct contact with the patient and the family.

\section{Discussion}

Convenience sample, in small in number and centered on a single teaching institution, limits the possibility of generalizing results to other populations.

This study was conducted with undergraduates attending the last year because researchers believed that previous experiences could contribute to their ability to communicate. A meta-analysis performed on the effectiveness of the simulation in nursing corroborates our perception, since it demonstrated that the simulation had maximum benefits for the nursing students of the last year, as the accumulated clinical experience can facilitate the construction of knowledge during the simulation, especially in clinical realistic situation $^{(14)}$.

Although learning related to nursing communication can improve the student's ability to interact effectively with patients, we found that there is a shortage of literature on the subject. Studies whose secondary results have focused on communication have shown that simulation, at different moments of nursing student training, can contribute to improve communication with the patient ${ }^{(15)}$.

Conducting communication simulations with actors allows for different constructions, since actors and students interact differently to each stimulus given by one or the other, participants of the phenomenon, increasing the opportunities for communication and discussion of it in debriefing ${ }^{(7)}$.

When analyzing the results of each statement of the Health Communication Assessment Tool, it was noticed that the communication skills scores of the nursing student in simulation with standardized patients were satisfactory.

The results of our study showed that students were prepared to maintain eye contact with the patient and the family and also to communicate what would be done before doing so. This data is reinforced in a recent qualitative study in which the nursing students stated that talking with the patient to inform what would be done took more time than they imagined, although it is a necessary action for a safe care ${ }^{(16)}$.

Although communication is an essential goal of care in order to satisfy the user in their health needs ${ }^{(17)}$, in our study many students had difficulty in addressing psychosocial aspects regarding the treatment and feelings that the patient and family could manifest at that time.

The nurse must consider that patient and the family have suffered the interruption of their social processes, with routine changes. Given the complexity of human relationships, meeting psychosocial needs ends up being one of the most difficult care to be im- 
plemented by the health team ${ }^{(18)}$.

By recording interviews conducted in virtual simulation between patients and 343 nursing students in eight states in the United States, nursing educators identified situations in which the patients expressed themselves in order to facilitate communication by the nurse, such as expressions of pain, difficulties in daily life, gaps in health education, lack of treatment and monitoring, discomfort with body image, loss of a family member, and counseling on drug consumption in the past. Of 3,087 empathic communication opportunities (nine for each of the 343 students), the students found 1,625 and responded to 545 of these opportunities, representing $33.5 \%$ of the total ${ }^{(17)}$.

During the debriefing conducted in this study, we could discuss the actions performed by the students in the interaction with the patient and the family. Many behaviors and words used were readily recognized by the participants as being amenable to improvement. It was possible to perceive that, in giving space to students to express their feelings, many of them reported a surprise with the presence of actors and the realism of the activity. We understand that debriefing helps students to consider what has been learned and how learning can be connected to previous learning and experiences in their lives ${ }^{(7)}$.

Another aspect mentioned by the students during the debriefing was the need to include simulation with actors at the beginning of the course, i.e., before the first contact with the patient and the family, in order to allow some previous experiences, providing an opportunity to learn from mistakes and to help the student to experience real life situations ${ }^{(7,11)}$.

Finally, we believe that the active discussion of communication evaluation results from the use of this tool can stimulate autonomy, responsibility and learning among nursing students. We also believe in the relevance of discussion about the inclusion of standardized patient simulation in nursing undergraduate curricula as a strategy for apprehending communication, considering it as a fundamental attribute of health care.

\section{Conclusion}

Nursing students' communication was satisfactory, however, there are gaps especially related to the patient and family's emotional aspects, which manifests the need to reinforce empathic communication in the nursing curriculum. In addition, students' speech during the debriefing enabled discussing the importance of the early insertion of simulation activities with standardized patients in students' training.

\section{Acknowledgements}

The authors of this study thank the participating actors: Hélio de Souza Porto, Jéssica Priscila Alves, Jéssica Priscila de Mélo and Johnnes Kowalski.

\section{Collaborations}

Góes FSN contributed to the project design, analysis and interpretation of the data, article writing and final approval of the version to be published. Aredes NDA contributed to the analysis and interpretation of the data, article writing and final approval of the version to be published. Hara CYN, Fonseca LMM and Campbell SH contributed to the relevant critical review of the intellectual content and final approval of the version to be published.

\section{References}

1. Kitson A, Marshall A, Bassett K, Zeitz K. What are the core elements of patient-centred care? A narrative review and synthesis of the literature from health policy, medicine and nursing. J Adv Nurs. 2013; 69(1):4-15.

2. Ministério da Educação (BR). Conselho Nacional da Educação. Camara de Educação Superior. Resolução no 3 de 7 de novembro de 2001: institui Diretrizes Curriculares Nacionais do Curso de Graduação em Enfermagem. Brasília: Ministério da Educação; 2001. 
3. Waznonis AR. Simulation debriefing practices in traditional baccalaureate nursing programs: National survey results. Clin Simul Nurs. 2015; 11(2):110-9.

4. Pagano M, Greiner P. Enhancing communication skills through simulation. In: Campbell SH, Daley K. Simulation scenarios for nurse educators: making it real. New York: Springer Publishing Company; 2013. p.17-24.

5. Pagano M. Health communication for health care professionals. New York: Springer Publishing Company; 2016.

6. Campbell SH, Pagano MP, O'Shea ER, Connery C, Caron C. Development of the health communication assessment tool: enhancing relationships, empowerment, and power-sharing skills. Clin Simul Nurs. 2013; 9(11):543-50.

7. Alconero-Camarero AR, Gualdrón-Romero A, Sarabia-Cobo CM, Martinez-Arce A. Clinical simulation as a learning tool in undergraduate nursing: validation of a questionnaire. Nurse Educ Today [Internet]. 2016 [cited 2017 Apr 18]; 39:128-34. Available from: http:// www.sciencedirect.com/science/article/pii/ S026069171600054X

8. National League for Nursing [Internet]. NLN Research Priorities in Nursing Education 2016 - 2019. [Internet]. 2016 [cited 2017 Apr 18]. Available from: http://www.nln.org/docs/ default-source/professional-developmentprograms/nln-research-priorities-in-nursingeducation-single-pages.pdf?sfvrsn=2.

9. Defenbaugh N, Chikotas NE. The outcome of interprofessional education: integrating communication studies into a standardized patient experience for advanced practice nursing students. Nurse Educ Pract. 2016; 16(1):176-81.
10. Efstathiou N, Walker WM. Interprofessional, simulation-based training in end of life care communication: a pilot. J Interprof Care. 2014; 28(1):68-70.

11. Spinner-Gelfars, AH. Using simulation to promote effective communication with a diverse student population. Teaching Learning Nurs. 2013; 8(3):96-101.

12. Miles LW, Mabey L, Leggett S, Stansfield K. Teaching communication and therapeutic relationship skills to baccalaureate nursing students: a peer mentorship simulation approach. J Psychosoc Nurs Ment Health Serv. 2014; 52(10):34-41.

13. Cooper A. High-fidelity simulation for neonatal nursing education: an integrative review of the literature. Neonatal Network: NN. 2015; 34(6):345-54.

14. Shin S, Park JH, Kim JH. Effectiveness of patient simulation in nursing education: meta-analysis. Nurse Educ Today. 2015; 35(1):176-82.

15. Bussard M. Self-reflection of video-recorded highfidelity simulations and development of clinical judgment. J Nurs Educ. 2016; 55(9):522-27.

16. Lestander O, Lehto N, Engström A. Nursing students' perceptions of learning after high fidelity simulation: effects of a three-step postsimulation reflection model. Nurse Educ Today [Internet]. 2016 [cited 2017 Apr 18]; 40:219-24. Available from: http://www.sciencedirect.com/ science/article/pii/S0260691716001179

17. Strekalova YA, Krieger JL, Kleinheksel AJ, Kotranza A. empathic communication in virtual education for nursing students: I'm sorry to hear that. Nurse Educ. 2017; 42(1):18-22.

18. Bautista R, Luz MFAV, Zury OCL. Percepción de los familiares de pacientes críticos hospitalizados respecto a la comunicación y apoyo emocional. Rev Cuidarte. 2016; 7(2):1297-309. 